\title{
A multi-criteria decision analysis approach to assessing malaria risk in northern South America
}

Temitope O. Alimi ${ }^{1 *}$, Douglas O. Fuller ${ }^{2}$, Socrates V. Herrera ${ }^{3,4}$, Myriam Arevalo-Herrera ${ }^{3,4}$, Martha L. Quinones ${ }^{5}$, Justin B. Stoler ${ }^{2,6}$ and John C. Beier ${ }^{6}$

\begin{abstract}
Background: Malaria control in South America has vastly improved in the past decade, leading to a decrease in the malaria burden. Despite the progress, large parts of the continent continue to be at risk of malaria transmission, especially in northern South America. The objectives of this study were to assess the risk of malaria transmission and vector exposure in northern South America using multi-criteria decision analysis.

Methods: The risk of malaria transmission and vector exposure in northern South America was assessed using multi-criteria decision analysis, in which expert opinions were taken on the key environmental and population risk factors.

Results: Results from our risk maps indicated areas of moderate-to-high risk along rivers in the Amazon basin, along the coasts of the Guianas, the Pacific coast of Colombia and northern Colombia, in parts of Peru and Bolivia and within the Brazilian Amazon. When validated with occurrence records for malaria, An. darlingi, An. albimanus and An. nuneztovari s.l., t-test results indicated that risk scores at occurrence locations were significantly higher $(p<0.0001)$ than a control group of geographically random points.

Conclusion: In this study, we produced risk maps based on expert opinion on the spatial representation of risk of potential vector exposure and malaria transmission. The findings provide information to the public health decision maker/policy makers to give additional attention to the spatial planning of effective vector control measures. Therefore, as the region tackles the challenge of malaria elimination, prioritizing areas for interventions by using spatially accurate, high-resolution (1 km or less) risk maps may guide targeted control and help reduce the disease burden in the region.
\end{abstract}

Keywords: Malaria, Malaria risk, Multi-criteria decision analysis, Risk maps, South America

\section{Background}

Malaria continues to exact a toll in many developing countries where it is endemic through the economic and health burden it imposes. Malaria has historically contributed to increased health costs, decreased productivity, and slow rates of economic growth in 80 developing countries [1]. An estimation in 2013 showed that about 198 million cases and 584,000 deaths related to malaria occurred globally [2]. Although sub-Saharan Africa bears

\footnotetext{
* Correspondence: t.alimi@umiami.edu

${ }^{1}$ Abess Center for Ecosystem Science and Policy, University of Miami, Coral Gables, FL, USA

Full list of author information is available at the end of the article
}

a disproportionately larger burden of the disease, South America also bears a significant case burden, with approximately 427,000 confirmed cases and 82 deaths in 2013 [2]. Of these, the nine countries in northern South America (NSA) accounted for $\sim 90 \%$ of the malaria cases in the continent [3]. Despite these figures, there have been vast improvements in malaria control in the past decade [2], so much so that malaria elimination in the NSA now seems feasible in the foreseeable future.

Global efforts to eliminate malaria such as the Roll Back Malaria program aim to "shrink the malaria map by progressively eliminating malaria from endemic margins inward" [4]. Achieving malaria elimination in the 
NSA, as in other region, will involve the systematic and synergistic use of multiple strategies including targeting areas for malaria interventions based on a stratification of risk. Spatially accurate, high-resolution risk maps delimiting areas of likely human-vector contact would not only help prioritize areas for malaria intervention, but also aid monitoring and evaluation of such interventions [5].

The stratification of risk depends on how risk is defined, yet there is currently no standard definition. Risk definitions have been dependent on the subject matter or purpose of the investigation [6]. Risk is broadly defined in public health as "the probability of disease developing in an individual in a specified time interval" [7]. Malaria risk is however not clearly defined due to the complexity of the disease that involves multiple hosts, vectors, and pathogens. Malaria risk has been defined using human cases (e.g. incidence and prevalence [8]), probability of Plasmodium presence [9], intensity of transmission [10], or its vectors (e.g. vector exposure [5], vector presence [11], and habitat suitability of vectors [12]). Thus, malaria risk is broadly considered as an array of factors that relate to the presence and density of vectors and parasites, all of which vary in space and time.

The direct estimation of malaria risk often involves malaria diagnosis and its relationship to populations at risk [13], but periodic, field-based survey data are typically limited in space and time in developing countries. Alternatively, in areas with limited data, malaria risk may be estimated indirectly through environmental covariates, which often show strong associations with malaria and mosquito distributions. The combination of these environmental surrogates in geographic information system (GIS) decision-support algorithms can reveal unexpected spatial patterns of malaria risk at unprecedented spatial resolutions [5]. Many types of spatial data derived from remotely sensed observations such as digital elevation models from the Shuttle Radar Topography Mission (SRTM) are now publicly available for most parts of the world, thus facilitating the potential estimation of malaria risk across large areas across multiple political units [5].

One method of mapping disease risk with limited field-based epidemiological or vector data is multicriteria decision analysis (MCDA). This approach is preferred for its participatory framework, which employs statistical methods and human intuition, allows expert interaction, and accommodates non-linear relationships common between disease organisms and the environment $[14,15]$. MCDA allows the combination of multiple environmental factors in estimating disease risk by employing decision rules derived from existing knowledge or hypothesized understanding of the causal relationships leading to disease occurrence $[5,15]$. The output is a composite map which indicates lower or higher potential of disease occurrence in a location relative to surrounding areas on the same map [16]. MCDA has been useful in assessing risk of vector-borne diseases such as predicting suitable areas for rift valley fever in Africa [17], prioritizing areas of tsetse fly control in Zambia [18], malaria vector control in Madagascar [19] and risk of malaria vector exposure in parts of South America [5]. Building on the work by Fuller et al. [5], we set out in this study to evaluate malaria risk in the NSA based on environmental factors to produce risk maps that could guide targeted malaria interventions and potentially accelerate the drive towards malaria elimination in the region.

\section{Methods}

\section{Study area}

The NSA comprises of Colombia, Ecuador, French Guiana, Guyana, Peru, Suriname, Venezuela, and parts of Bolivia and Brazil (Fig. 1). The climate of the NSA is predominantly tropical, i.e., hot, wet and humid, especially within the Amazon rainforest and along the Atlantic and Pacific coasts [20]. Areas in the East around the Andes have high elevations (average height of 4, $000 \mathrm{~m}$ ) and cooler weather (mean temperature range $\left.18-22{ }^{\circ} \mathrm{C}\right)$ [21]. The vegetation follows a similar pattern: the tropical rainy regions and the Amazon basin have dense rainforests, while the savannas dominate in areas of highly seasonal rainfall such as the Llanos of Colombia and Venezuela and parts of central Brazil [22]. Vegetation along the humid slopes of the Andes also vary as elevation increases, with tropical trees at lower altitudes giving way to sub-tropical trees and finally grasses at higher elevations [22]. The countries also exhibit socio-economic differences which affect land use patterns and invariably disease incidence. For example, the large-scale soybean production in Brazil has not only led to increased revenue from external trade, but also higher deforestation [23], which has been linked to increased malaria and mosquitoes [24, 25].

Amongst the reported malaria infections in the NSA, Plasmodium vivax accounted for $75 \%$, followed by $P$. falciparum (25\%) [2]. Although malaria control is firmly established in the nine countries and reported cases are declining, only Ecuador is currently in the preelimination phase [2]. Many Anopheles vectors have been implicated in malaria transmission in the region [11, 26], and An. albimanus (Wiedemann 1820), An. darlingi (Root 1926) and An. nuneztovari s.l. (Gabaldon 1940) are the dominant species. All three vectors can transmit both $P$. falciparum and $P$. vivax $[25,27]$ and are anthropophilic $[28,29]$. They are night biters exhibiting exophagic and exophilic feeding [27, 30-35]. They 

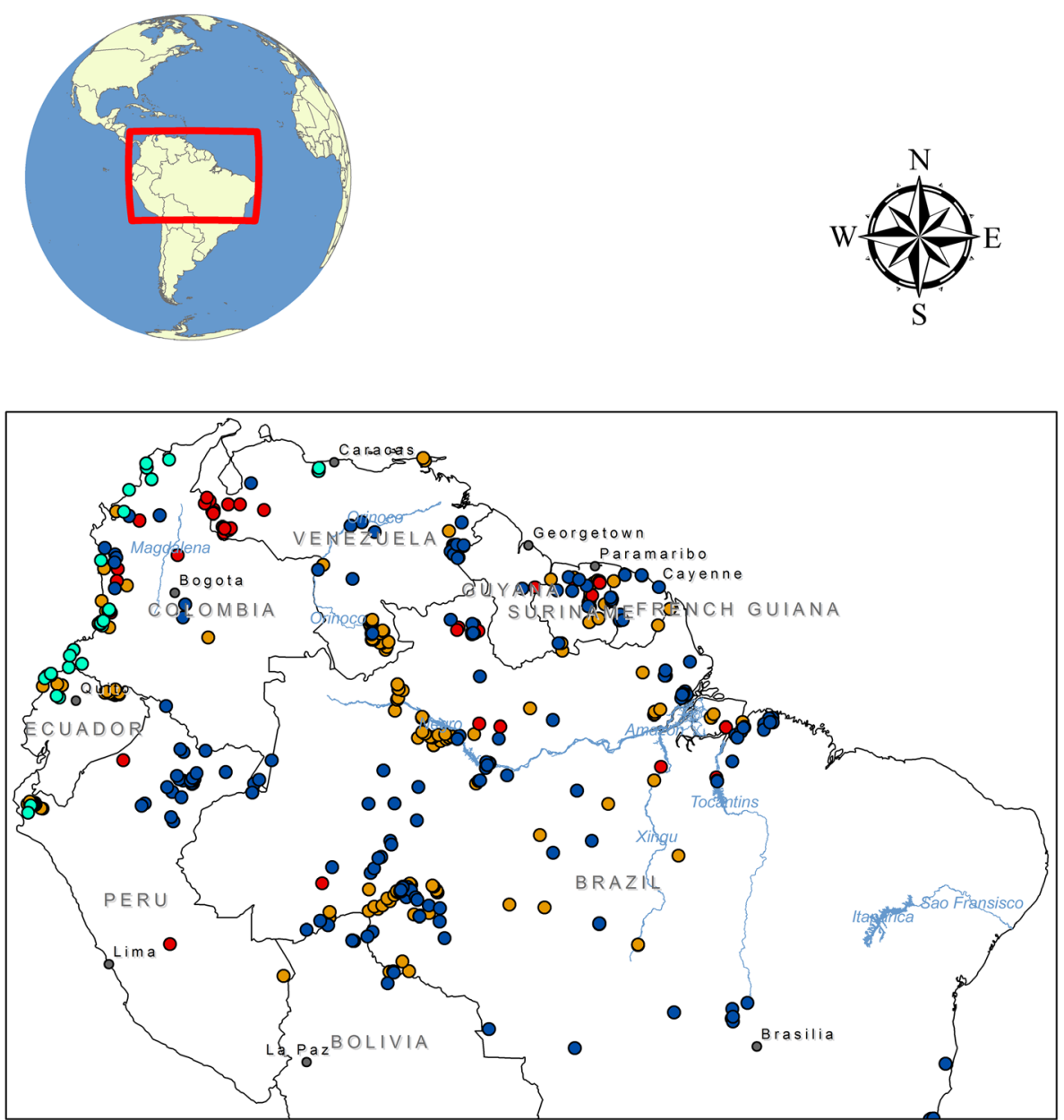

\section{Legend}

- An. albimanus
- An. darlingi
- An. nuneztovari
- Malaria
- National Capitals
Water bodies
Country boundaries

Fig. 1 Map of the NSA showing An. albimanus, An. darlingi, An. nuneztovari s.l. and malaria sample locations

have been found in a wide range in the study area, including Colombia [34, 36], Amazonian plains of Ecuador [37], the Amazonian South and western Venezuela [38] and Brazil [39].

\section{Data sources}

Sample locations for both parasite species were obtained through the Malaria Atlas Project (MAP) website. The data comprises surveys conducted by researchers and organizations between 1985 and 2009 in the various countries. Downloaded data also contained geo-referenced location of cases, the diagnostic method used for detection, age, the number of individuals examined, and number of individuals with parasites in the blood. Similar georeferenced data (Fig. 1) for the 3 vector species were obtained through the Walter Reed Biosystematic Unit [40] and the Global Biodiversity Information Facility [41]. These records included locations where both larvae and adult $A n$. darlingi, An. albimanus and $A n$. nuneztovari s.l had been sampled by different investigators between 1980 and 2007.

\section{Variable selections}

Nine parameters associated with the environment, including climate were chosen based on their association malaria and its vectors (Table 1). These included factors 
Table 1 Risk factors and fuzzy membership functions used to create risk maps

\begin{tabular}{|c|c|c|c|c|c|}
\hline Data & Source & Factor & Control points & Fuzzy function & Rationale \\
\hline Deforestation & Global Forest change [54] & Distance (km) & 0,5 & Linear $\downarrow$ & Vectors are found within $5 \mathrm{~km}$ of deforested areas \\
\hline Elevation & SRTM $90 \mathrm{~m}$ & Elevation (m) & 500,1800 & J-shaped $\downarrow$ & $\begin{array}{l}\text { Exposure to vectors decrease above } 500 \mathrm{~m} \text { and is } \\
\text { non-existent above } 1800 \mathrm{~m}\end{array}$ \\
\hline Population & LandScan & Population density & $2,50,100,150$ & Sigmoidal $\uparrow \downarrow$ & $\begin{array}{l}\text { Populations between } 2 \text { and } 150 / \mathrm{km}^{2} \text { are sufficient } \\
\text { for malaria transmission }\end{array}$ \\
\hline Precipitation & WorldClim & Precipitation (mm) & 0,80 & Linear $\uparrow$ & $\begin{array}{l}\text { Precipitation of } 80 \mathrm{~mm} \text { is suitable for vectors for } \\
\text { stable transmission to occur [43] }\end{array}$ \\
\hline Roads & DCW & Distance (km) & 0,5 & Linear $\downarrow$ & $\begin{array}{l}\text { Transmission occurs within } 5 \mathrm{~km} \text { of roads where } \\
\text { blood meals are available }\end{array}$ \\
\hline Temperature & WorldClim & Temperature ${ }^{\circ} \mathrm{C}$ & $18,22,32,40$ & Sigmoidal $\uparrow \downarrow$ & $\begin{array}{l}\text { Sporogony starts at } 18^{\circ} \mathrm{C} \text { and is completed at } 22^{\circ} \mathrm{C} \text {, } \\
\text { vector survival decreases above } 32^{\circ} \mathrm{C} \text { and death } \\
\text { occurs at } 40^{\circ} \mathrm{C} \text { [43] }\end{array}$ \\
\hline TWI & SRTM $90 \mathrm{~m}$ & Soil Saturation (\%) & 0,5 & Linear $\uparrow$ & $\begin{array}{l}\text { An area requires about } 5 \% \text { water saturation to } \\
\text { serve as breeding site }\end{array}$ \\
\hline Urban areas & DeLorme, Inc. & Distance (km) & $1,10,20,30$ & Sigmoidal $\uparrow \downarrow$ & $\begin{array}{l}\text { Vectors are absent in urban areas but found in the } \\
\text { urban periphery }\end{array}$ \\
\hline Wetlands & WWF & Distance (km) & 0,3 & Linear $\downarrow$ & Vectors are found within $3 \mathrm{~km}$ of wetlands \\
\hline
\end{tabular}

Abbreviations and Symbols: SRTM Shuttle Radar Topography Mission, DCW Digital Chart of the World, WWF World Wildlife Fund. The $\uparrow$ arrows indicates an increasing function, $\downarrow$ a decreasing function and $\uparrow \downarrow$ a symmetric function

related to availability of vector breeding sites (wetlands, precipitation and topographic wetness index -TWI, which was derived from the digital elevation model), thermal and altitudinal limits for parasites and vectors (elevation and temperature), and access to blood meals (population density, roads, urban areas and deforestation).

\section{Procedure}

\section{Risk map generation}

Two data layers (elevation and TWI) were resampled to $1 \mathrm{~km}$ spatial resolution to maintain consistency with the other layers originally provided at $1 \mathrm{~km}$. Resampling was carried out using the nearest neighbor algorithm, which preserves original data values. A binary discrete raster was created from the elevation layer to serve as a constraint, excluding areas with elevation $>1800 \mathrm{~m}$ where risk of transmission was assumed to be negligible [5]. Because the influence of categorical variables on risk of malaria and vector exposure was based on access (Table 2), we created distance layers measuring proximity to the features before further analyses.

The data layers contained variably scaled information; hence, fuzzy functions were employed to standardize all the layers to a common data range needed to facilitate factor integration. Fuzzy functions measure the degree

Table 2 Factor groupings and weights used for risk maps

\begin{tabular}{|c|c|c|c|c|c|}
\hline \multirow[t]{2}{*}{ Factor } & \multirow[t]{2}{*}{ Factor groupings } & \multicolumn{4}{|c|}{ Factor weight } \\
\hline & & $\mathrm{AHP}^{\mathrm{a}}$ & Equal $^{b}$ & Access related $^{c}$ & Environment/Climate related $^{\mathrm{d}}$ \\
\hline Distance from deforested patches & Access & 0.0996 & $\sim 0.11$ & 0.14 & 0.06 \\
\hline Population density & & 0.0593 & & & \\
\hline Distance from roads & & 0.0379 & & & \\
\hline Distance from urban areas & & 0.0420 & & & \\
\hline Distance from wetlands & & 0.1391 & & & \\
\hline Elevation & Environmental/Climatic & 0.1680 & & 0.075 & 0.175 \\
\hline Precipitation & & 0.1784 & & & \\
\hline Temperature & & 0.2006 & & & \\
\hline TWI & & 0.0751 & & & \\
\hline
\end{tabular}

${ }^{\mathrm{a} F a c t o r s}$ weighed based on ecological relationship with mosquitoes and malaria

${ }^{\mathrm{b}}$ No difference in weighting

'Access more important (group weight sum up to 0.70)

${ }^{d}$ Environment/Climate related factors more important (group weight sum up to 0.70 )

TWI Topographic Wetness Index 
of membership of data cells in a layer through control points that are set based on the relationship between the layer and disease/vectors. These relationships determine the shape (linear, sigmoidal or J-shaped) and direction (increasing, decreasing or symmetric) of the fuzzy function (See Table 1), which were represented on an 8-bit $(0-255)$ scale in our analysis. For instance, we used a linear decreasing function to scale risk associated with access to blood meals such as deforestation by assuming highest risk when close and no risk when more than $5 \mathrm{~km}$ away from the feature.

Prior to use in the MCDA, each fuzzy layer was assigned a weight indicating its importance in the risk assessment. To facilitate the process of weighting, the nine factors were combined into two logical groups: (i) access-related factors relying on distance/proximity to features; and (ii) environment/climate related factors (Table 2). Weights were subsequently assigned in four ways: (i) by weighing all factors equally; (ii) assigning higher weights to access-related variables; (iii) scaling environment/climate related factors higher (approximately three-quarters of total weights assigned to group of factors with higher weighting in each case); and (iv) assigning weights based on interaction between factors and disease/vectors using the analytical hierarchical process (AHP). The AHP assigns weights to each factor by assessing the relative importance of factor pairs in a pairwise matrix [42]. Pair comparisons were conducted by evaluating the importance of each factor relative to the other in a pair and assigning values ranging from 1 (extremely less important) to 9 (extremely more important). Evaluation for 6 of the factors were carried out by a group of malaria experts in a risk mapping workshop in Cali, Colombia (details of procedure published elsewhere [5]). Our ranking of the other 3 factors was based on literature searches by which we determined that temperature, precipitation, and deforestation be ranked in descending order [43]. The principal eigenvector was subsequently used to determine the final weight of each factor. The consistency of the pairwise matrix was evaluated using a threshold of 0.1 , a ratio above which the pairwise matrix should be revised while values below indicate acceptable consistency [42]. Table 2 shows all factor weights assigned using the AHP and the other methods.

Finally, the multi-criteria evaluation (MCE) module was used to integrate all data layers to create composite risk maps for the study area. A number of user-specified options exist in the MCE module for this purpose but for our analysis, we chose the weighted linear combination (WLC). The WLC is a linear function which combines fuzzy layers according to their weight of importance (all factor weights add up to 1 ) [5, 44, 45], producing final composite maps of risk based on the four weighting methods. All analyses were conducted using the raster-based GIS software, Idrisi (Selva edition) [45].

\section{Assessment of risk maps from sample points}

Resulting risk maps were evaluated by comparing differences in mean risk scores between randomly generated points $(n=1502)$ and the risk scores at the sample locations of An. darlingi $(n=168)$, An. albimanus $(n=38)$, An. nuneztovari s.l. $(n=114)$ and malaria cases $(n=218)$ respectively. Assuming normal distribution, differences between the mean risk scores for each vector and malaria occurrence points and random control points were assessed using unpaired $t$-test. A one-way analysis of variance (ANOVA) was used to compare the means of the four groups of sample points. Both statistical analyses were performed in SPSS v. 21 software [46]. Spatial autocorrelation of the sample points was tested using the Moran's I statistic in ArcGIS 10.2 software [47]. Moran's $I$ tests the null hypothesis that the attribute of the feature of interest is randomly distributed where a statistically significant $Z$-score indicates spatial autocorrelation. To correct autocorrelation found in sample points, we systematically excluded points until arriving at a distribution that was spatially independent.

\section{Results}

\section{Malaria risk distribution}

The composite maps of risk produced using the four weighting methods are presented in Fig. 2a-d. In Fig. 2a, the risk map was produced by assigning an equal weight of 0.11 to each of the twelve factors. The composite layer in Fig. $2 \mathrm{~b}$ included all the factors weighted through AHP. All five access-related factors in Fig. 2c were assigned equal weights, which summed up to 0.7 , thus giving access-related factors a higher weighting than environment-related factors which had a total of 0.3. For Fig. 2d these weightings were reversed; the four environment-related factors were given a cumulative value of 0.7 while access-related factors were assigned a total of 0.3 .

The different maps reveal noticeable differences in the level and distribution of risk. For instance, the distribution of risk in Fig. 2c is more heterogeneous compared to the other maps. In this composite layer, the Amazonian areas of Brazil, Venezuela, Colombia, the Guianas, and Peru, as well as southern Brazil and areas on the fringes of the Andes display low risk scores relative to areas outside the Amazon basin. The relatively higher weight given to access-related factors may account for this distribution particularly in the Amazon, as the area is associated with low population density and limited access via roads and rivers, hence the lower imputed risk. Areas of relatively moderate to high risk on this 




Fig. 2 Risk maps derived from weighted linear combination of 9 factors. Higher values indicate relatively higher risk scaled from 0 to 255 . a Each factor assigned an equal weight of 0.11 ; b Factors weighed according to ecological relationship with mosquitoes and malaria through AHP; c Access was assigned more weight (0.7 out of 1); d Environmental/Climatic factors was given more weight (0.7 out of 1)

map were found mostly along stretches of rivers in the Amazon basin, along the coasts of the Guianas, in the seasonally flooded wetlands around the Llanos, in patches around south-western Brazil, in areas west of the Andes in Peru and Bolivia, along the coasts of Ecuador and Colombia, and in northern Colombia.

The areas delineated as moderate to high risk locations in Fig. 2c are common to all the maps; however, additional areas of high risk are highlighted in the other maps. Contrary to what was shown in Fig. 2c, the Amazon forest had elevated risk of transmission, particularly in the AHP guided map (Fig. 2b), which displays moderate risk relative to the other maps. In the equally weighted map (Fig. 2a), moderate to low risk can be seen especially throughout the Amazon basin, Southern Venezuela, and central Brazil. Although the AHP and the environment -related maps (Fig. 2b and $\mathrm{d}$ respectively) appear similar because the total weight assigned to environmental factors in both maps was similar (0.6221 and 0.7 respectively), differences in the maps are evident. High risk areas in Fig. $2 \mathrm{~b}$ are displayed along the rivers in the Amazon basin, the wetlands, and along the coasts in the study area whereas risk is depicted in a spatially homogeneous fashion in Fig. 2d. Overall, similar areas of low risk are displayed in central Brazil, southern
Venezuela and the Andean fringe while the high risk areas identified in all the maps are consistent with current understanding of malaria risk in the region $[48,49]$.

\section{Validation of risk maps from sample points}

The test for spatial autocorrelation showed that vector occurrence points for An. darlingi (Moran's I $=0.036$, $\mathrm{z}=0.07, p=0.94$ ) and An. albimanus (Moran's $\mathrm{I}=$ $0.458, \mathrm{z}=0.68, p=0.39$ ) were spatially random within the study area. Autocorrelation was detected in $A n$. nuneztovari s.l (Moran's $\mathrm{I}=0.758, \mathrm{z}=2.902, p=0.03$ ) and malaria (Moran's $\mathrm{I}=747, \mathrm{z}=8.632, \quad p=0.00$ ) occurrence points. The $z$-scores however remained significant after systematically reducing the number of sample points ( $n=90$ and 172 for An. nuneztovari s.l and malaria respectively), thus suggesting that spatial dependence did not significantly influence results. Figure 3 shows the means from the MCE risk maps for the validation points. The $t$-test results indicated that mean cell-level risk scores at the occurrence locations were significantly different and higher $(p<0.0001)$ than risk scores of the random points (Table 3). Output from the one-way ANOVA test performed on 467 observations (Table 3: between and within group df) showed no significant difference in mean risk scores 


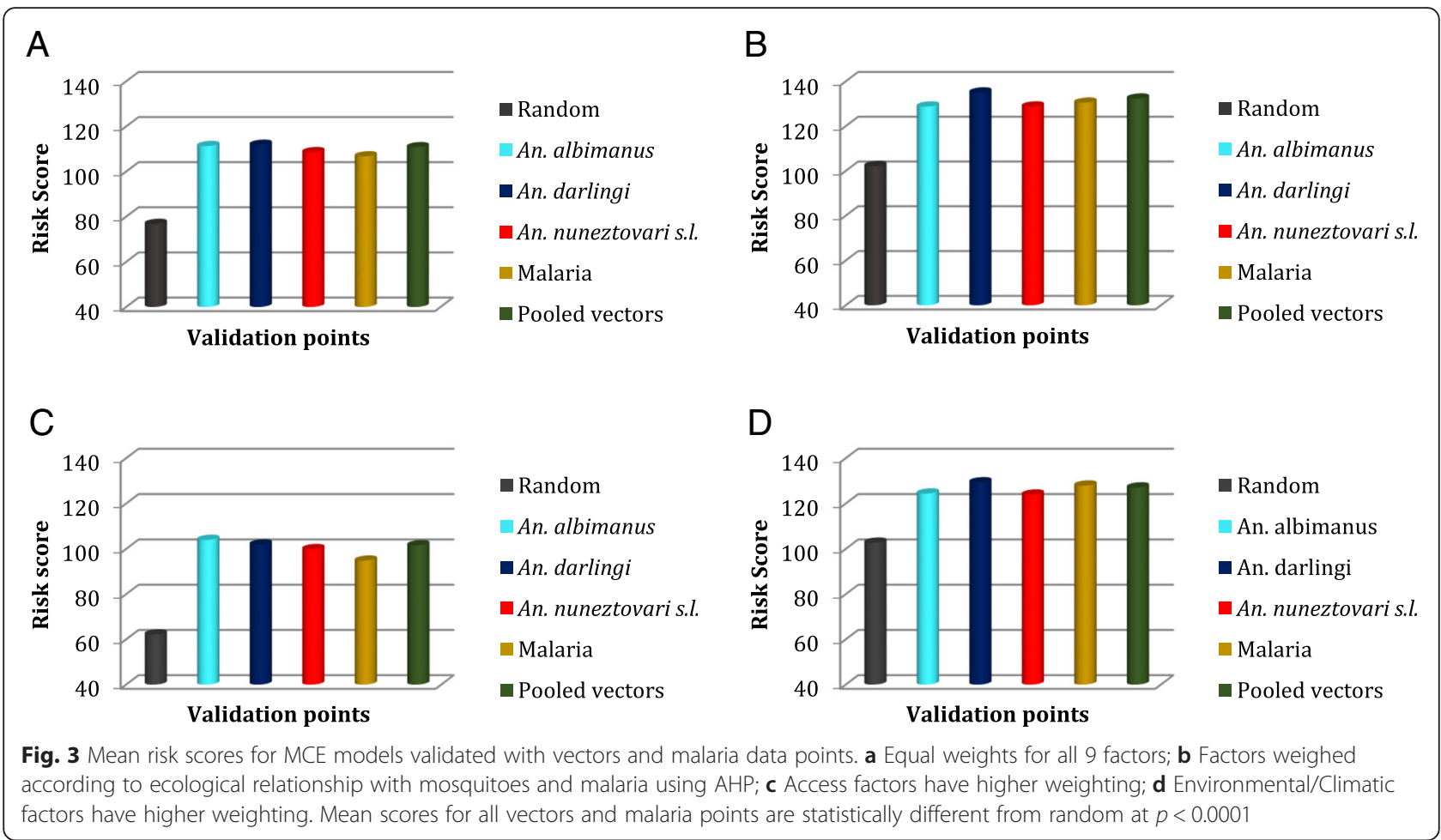

among occurrence points, suggesting that the occurrence points may be pooled into a single sample. Further analysis with $t$-test indicated that the pooled vector points were significantly different and higher $(p<0.0001)$ than randomly distributed points (Table 3).

\section{Discussion}

Spatial distribution of vector exposure and malaria risk Using publicly available environmental, vector, and case data, our study elucidates the spatial distribution of malaria and potential vector exposure risk and provides important spatial information that may guide targeted malaria interventions in the region. Although the environmental parameters typically change very little or gradually over time [5], the inclusion of a deforestation measure reflects a highly dynamic landscape variable that is strongly associated with malaria risk. This is exemplified in our four composite maps, which show most areas in the Amazon and southern Brazil where deforestation has been most pronounced in the past decade [50] as having moderate-to-high risk of malaria.

Although there are common areas with moderate to high risk on all four maps, there are also areas of model over-estimation. While the risk surface in Fig. 2b aligns relatively well with known malaria risk [48, 49], the

Table 3 Validation of risk maps using t- test and One-way ANOVA

\begin{tabular}{|c|c|c|c|c|c|c|c|}
\hline \multirow[t]{5}{*}{ Models } & \multicolumn{7}{|l|}{ Validation points } \\
\hline & \multicolumn{5}{|l|}{$t$ statistic } & \multicolumn{2}{|l|}{ ANOVA } \\
\hline & & & & & & \multirow{3}{*}{$\begin{array}{l}\text { Between groups (df) } \\
\text { Within group (df) } \\
\text { F statistic }^{b}\end{array}$} & \multirow{3}{*}{$\begin{array}{l}3 \\
464 \\
p \text {-value }\end{array}$} \\
\hline & & & & & & & \\
\hline & An. albimanus ${ }^{a}$ & An. darlingia & An. nuneztovaria & Malaria $^{a}$ & Pooled vectors ${ }^{a}$ & & \\
\hline $\mathrm{AHP}$ & 6.12 & 15.44 & 9.35 & 13.47 & 18.23 & 1.94 & 0.12 \\
\hline Equal & 8.61 & 17.70 & 12.05 & 15.32 & 21.67 & 1.15 & 0.33 \\
\hline Access & 9.77 & 18.57 & 13.33 & 15.49 & 23.06 & 1.84 & 0.14 \\
\hline Environment/Climatic & 5.05 & 12.77 & 7.57 & 12.20 & 15.04 & 1.51 & 0.21 \\
\hline
\end{tabular}

${ }^{\text {aStatistically different from random at } p<0.0001}$

${ }^{\mathrm{b} C o m p a r i s o n}$ of means for An. albimanus, An. darlingi, An. nuneztovari and Malaria cases 
result of the access-related grouping is similar to that produced by Fuller et al. [5] for parts of the study area. Overall, based on Figs. 2 and 3, A and C provide a more realistic depiction of risk; however, it should be noted that malaria transmission does not occur along the Atlantic Coast of Brazil south of the Amazon basin; therefore, what the maps depict is more likely a better representation of risk of vector exposure than actually malaria transmission. Risk was however over-estimated in all four maps in areas around central and along the Atlantic Coast of Brazil south of the Amazon Basin where urbanization, transportation infrastructure, and environmental factors have favored vector control.

The consistently higher mean risk scores for $A n$. darlingi and An. albimanus may also reflect their importance in malaria transmission in the region $[25,27,51]$. While $A n$. darlingi is the predominant vector in the study area [27], An. albimanus is more wide spread particularly in Colombia and the northern-most portions of the study region [51].

\section{Comparison with previous studies}

Further, whereas many previous risk-mapping exercises focus on individual political units, these maps show how risk is represented across political boundaries, whether national or local $[48,49]$. While previous malaria risk maps show current risk based on actual malaria cases aggregated by municipalities [48, 49], our composite maps the effects of environmental and climatic conditions and their perceived degree of association with vectors and malaria transmission [5, 52]. Our approach avoids limitations of aggregating cases by municipality (e.g. giving no indication of the location of transmission or clustering of cases) by producing a continuous risk surface with high spatial detail and clearly defined risk gradients.

Unlike the weak relationship reported between malaria cases represented by municipalities and mean risk scores in Fuller et al. [5], mean risk scores for malaria points used in this study were consistently higher than at random locations. This may be the result of employing georeferenced malaria point locations as this is more easily relatable to pixel-level risk scores than political units represented as polygons.

\section{Study limitations}

The subjective nature of the MCDA approach in assigning fuzzy functions and weights undoubtedly produces some biased outcomes as well as probable inflation of risk scores when correlated variables are used [5, 15]. We also acknowledge the possibility of temporal and geographical bias in the sampling of occurrence points as a result of multiple collectors and the variable time of collection. Moreover, the dearth of up-to-date secondary and tertiary road network data for the study area may also have limited the estimation of risk based on access to roads, particularly in the northern parts of the study area.

\section{Conclusion}

We evaluated the exposure of the NSA to malaria risk given current access-related and environmental/climatic conditions using MCDA. We produced high-resolution composite maps showing gradients of risk which were validated with geo-coded occurrence points for malaria and three dominant vector species. These new map products represent an improvement upon previously published map of malaria risk in the region, which was highly generalized and constrained by political boundaries $[50,53]$. The incorporation of a deforestation layer representing land-use change, provided additional detail to the risk maps relative to past studies that have employed MCDA for malaria vector exposure risk [5]. This also revealed that our depiction of risk produced was related to malaria occurrence points. Despite limitations of the knowledge-based approach to risk mapping, our $1 \mathrm{~km}$ maps provide information to the public health decision makers/policy makers to give additional attention to the spatial planning of effective vector control measures. This may increase the potential for malaria elimination in the region in the near future.

\section{Ethics approval}

Ethical clearance was not sought because human subjects were not involved.

\section{Abbreviations}

AHP: analytical hierarchical process; ANOVA: analysis of variance; GIS: geographic information system; MAP: malaria atlas project; MCDA: multicriteria decision analysis; MCE: multi-criteria evaluation; NSA: Northern South America; TWl: topographic wetness index; WLC: weighted linear combination.

\section{Competing interests}

The authors declare that they have no competing interests.

\section{Authors' contributions}

TOA and DOF conceptualized the idea for the manuscript and wrote the draft. TOA conducted the analysis; SVH, MAH, MLQ, JBS and JCB critically revised the intellectual content of the manuscript. All authors read and approved the final manuscript.

\section{Acknowledgements}

We wish to thank Chris Hanson of the Geospatial Laboratory, University of Miami for providing resource and technical assistance. The research was supported by NIH ICEMR grant: Centro Latino Americano de Investigación en Malaria (CLAIM) sponsored by NIAID/ICEMR (U19A1089702), Colciencias (719-2013). We also acknowledge the reviewers whose inputs helped to improve the manuscript.

\section{Author details}

Abess Center for Ecosystem Science and Policy, University of Miami, Coral Gables, FL, USA. ${ }^{2}$ Department of Geography and Regional Studies, University of Miami, Coral Gables, FL, USA. ${ }^{3}$ Centro de Investigación Científica Caucaseco, Cali, Colombia. ${ }^{4}$ Faculty of Health, Universidad del Valle, Cali, 
Colombia. ${ }^{5}$ Department of Public Health, Universidad Nacional de Colombia, Bogota, Colombia. ${ }^{6}$ Department of Public Health Sciences, Miller School of Medicine, University of Miami, Miami, FL, USA.

\section{Received: 28 August 2015 Accepted: 22 February 2016} Published online: 03 March 2016

\section{References}

1. Sachs J, Malaney P. The economic and social burden of malaria. Nature. 2002:415:680-5

2. World Health Organization. World malaria report. Geneva, 2014

3. Pan American Health Organization. Programa Regional de Acción y Demostración de Alternativas Sostenibles para el Control de Vectores de la Malaria sin Uso de DDT en México y América Central, Mexico. Washington: 2008

4. Roll Back Malaria Partnership. Global Malaria Action Plan for a malaria free world. Geneva: 2008

5. Fuller DO, Troyo A, Alimi T, Beier JC. Participatory risk mapping of malaria vector exposure in northern South America using environmental and population Data. Appl Geo. 2014;48:1-7.

6. Sedda L, Morley DW, Braks MA, De Simone L, Benz D, et al. Risk assessment of vector-borne diseases for public health governance. Public Health. 2014:128(12):1049-58.

7. Dicker R, Coronado F, Koo D, Gibson PR. Principles of epidemiology in public health practice. 3rd ed. Maryland: Public Health Foundation; 2006.

8. Chaparro P, Padilla J, Vallejo AF, Herrera S. Characterization of a malaria outbreak in Colombia in 2010. Malar J. 2013;12:33.

9. Noor AM, Gething PW, Alegana VA, Patil AP, Hay SI, et al. The risks of malaria infection in Kenya in 2009. BMC Inf Dis. 2009;9:180.

10. Castillo-Salgado C. Epidemiological risk stratification of malaria in the Americas. Mem Inst Oswaldo Cruz. 1992;87 Suppl 3:115-20.

11. Sinka ME, Rubio-Palis $Y$, Manguin S, Patil AP, Temperley $W H$, et al. The dominant Anopheles vectors of human malaria in the Americas: occurrence data, distribution maps and bionomic précis. Parasit Vectors. 2010;3:72

12. Zeilhofer P, dos Santos ES, Ribeiro AL, Miyazaki RD, dos Santos MA. Habitat suitability mapping of Anopheles darlingi in the surroundings of the Manso hydropower plant reservoir, Mato Grosso, Central Brazil. Int J Health Geogr. 2007;6:7.

13. Baird JK, Bangs MJ, Maguire JD, Barcus MJ. Epidemiological measures of risk of Malaria. In: Doolan D, editor. Malaria Methods and Protocols. New Jersey: Humana Press; 2002. p. 13-22.

14. Hongoh V, Hoen AG, Aenishaenslin C, Waaub JP, Belanger D, et al. Spatially explicit multi-criteria decision analysis for managing vector-borne diseases. Int J Health Geogr. 2011:10:70.

15. Stevens KB, Pfeiffer DU. Spatial modeling of disease using data and knowledge driven approaches. Spat and Spatio-temp Epi. 2011:2:125-33.

16. Stevens K, de Glanville W, Costard S, Metras R, Theuri W et al. Mapping the likelihood of introduction and spread of highly pathogenic Avian Influenza Virus H5N1 in Africa and Indonesia using multi-criteria decision modelling. HPAI Research Brief No. 7 - Year: 2009.

17. Clements AC, Pfeiffer DU, Martin V. Application of knowledge-driven spatial modelling approaches and uncertainty management to a study of Rift Valley fever in Africa. Int J Health Geogr. 2006;5:57.

18. Symeonakis E, Robinson T, Drake N. GIS and multiple-criteria evaluation for the optimisation of tsetse fly eradication programmes. Environ Monit Asess. 2007;124:89-103.

19. Rakotomanana F, Randremanana R, Rabarijaona L, Duchemin J, Ratovonjato J, et al. Determining areas that require indoor insecticide spraying using multi criteria evaluation, a decision- support tool for malaria vector control programmes in the Central Highlands of Madagascar. Int J Health Geog. 2007;6:2.

20. South America Climate. http://www.mapsofworld.com/south-america/ geography/south-america-climate.html. Accessed 19 May 2015.

21. Garreaud RD, Mathias Vuille M, Compagnucci R, Marengo J. Present-day South American climate. Palaeogeography, Palaeoclimatology, Palaeoecology. 2009;281(3-4):180-95.

22. South America Continent. Encyclopedia Britannica. http://www.britannica com/EBchecked/topic/555844/South-America/41776/Plant-life. Accessed 19 May 2015.

23. Morton DC, DeFries RS, Shimabukuro YE, Anderson LO, Arai E, et al. Cropland expansion changes deforestation dynamics in the southern Brazilian Amazon. Proc Natl Acad Sci USA. 2006;103(39):14637-41.
24. Olson SH, Gangnon R, Silveira GA, Patz JA. Deforestation and malaria in Mâncio Lima County, Brazil. Emerging Infect Dis. 2010;16:1108-15.

25. Vittor AY, Gilman RH, Tielsch J, Glass G, Shields T, et al. The effect of deforestation on the human-biting rate of Anopheles darlingi, the primary vector of falciparum malaria in the Peruvian Amazon. Am J Trop Med Hyg 2006;74(1):3-11.

26. Arévalo-Herrera M, Quiñones ML, Guerra C, Céspedes N, Giron S, et al. Malaria in selected non-Amazonian countries of Latin America. Acta Tropica. 2012:121:303-14.

27. Hiwat H, Bretas G. Ecology of Anopheles darlingi Root with respect to vector importance: a review. Parasit Vectors. 2011:4:177.

28. Olano V, Carrasquilla G, Mendez F. Transmision de la malaria urbana en Buenaventura, Colombia: aspectos entomologicos. Rev Panam Salud Publica. 1997;1:287-94

29. Manguin S, Roberts DR, Andre RG, Rejmankova E, Hakre S. Characterization of Anopheles darlingi (Diptera: Culicidae) larval habitats in Belize, Central America. J Med Entomol. 1996:33:205-11.

30. Fritz GN, Conn J, Cockburn A, Seawright J. Sequence analysis of the ribosomal DNA internal transcribed spacer 2 from populations of Anopheles nuneztovari s.l. (Diptera: Culicidae). Mol Biol Evol. 1994;11:406-16.

31. Arredondo-Jiménez JI, Bown DN, Rodriguez MH, Villarreal C, Loyola EG, et al. Tests for the existence of genetic determination or conditioning in host selection by Anopheles albimanus (Diptera: Culicidae). J Med Entomol. 1992;29(5):894-7.

32. Roberts DR, Manguin S, Rejmankova E, Andre R, Harbach RE, et al. Spatial distribution of adult Anopheles darlingi and Anopheles albimanus in relation to riparian habitats in Belize, Central America. J Vector Ecol. 2002;27:21-30.

33. Mekuria Y, Tidwell MA, Williams DC, Mandeville JD. Bionomic studies of the Anopheles mosquitoes of Dajabon, Dominican Republic. J Am Mosq Cont Assoc. 1990;6:651-7.

34. Quiñones M, Suárez M, Fleming G. Distribución y bionomía de los anofelinos de la Costa Pacífica de Colombia. Colombia Med. 1987;18:19-24.

35. Charlwood JD. Biological variation in Anopheles darlingi Root. Mem Inst Oswaldo Cruz. 1996:91:391-8.

36. Olano VA, Brochero H, Saenz R, Quinones ML, Molina JA. Mapas preliminaries de la distribution de species de Anopheles vectores de malaria en Colombia. Biomedica. 2001;21:402-8.

37. Rodriguez MH. Malaria and dengue vector biology and control in Latin America. http://edepot.wur.nl/136957. Accessed 19 May 2015.

38. Rubio-Palis Y, Curtis CF. Biting and resting behaviour of anophelines in western Venezuela and implications for control of malaria transmission. Med Vet Entomol. 1992;6:325-34.

39. de Arruda M, Carvallo MB, Nussenzweig RS, Maracic M, Ferreira AW, et al. Potential vectors of malaria and their different susceptibility to Plasmodium falciparum and Plasmodium vivax in northern Brasil identified by immunoassay. Am J Trop Med Hyg. 1986;35:873-81.

40. Walter Reed Biosystematics Unit. http://www.wrbu.org/. Accessed 23 Sept 2013.

41. Global Biodiversity Information Facility. http://www.gbif.org/. Accessed 23 Sept 2013.

42. Saaty TL. Highlights and critical points in the theory and application of the analytic hierarchy process. Eur J Oper Res. 1994:74:426-47.

43. Craig MH, Snow RW, le Sueur D. A Climate-based distribution model of malaria transmission in Sub-Saharan Africa. Parasitol Today. 1999:15(3):105-11.

44. Fuller DO, Meijaard E, Christy L, Jessup TC. Mapping threats to biodiversity within ecoregions: an example from East Kalimantan, Indonesia. Appl Geo. 2010;30:416-25

45. Eastman RE. IDRISI 17: The Selva edition. Worcester: Clark Labs, Clark University; 2012

46. IBM Corp. IBM SPSS Statistics for Windows: Version 21.0. Armonk, NY; 2012

47. Environmental Systems Research Institute. ArcGIS Desktop: Release 10.2. Redlands, CA; 2014.

48. Herrera S, Quiñones ML, Quintero JP, Corredor V, Fuller DO, et al. Prospects for malaria elimination in non-Amazonian regions of Latin America. Acta Tropica. 2012:121:315-23.

49. da Silva-Nunes M, Moreno M, Conn JE, Gamboa D, Abeles S, et al. Amazonian malaria: asymptomatic human reservoirs, diagnostic challenges, environmentally driven changes in mosquito vector populations, and the mandate for sustainable control strategies. Acta Tropica. 2012;121:281-91.

50. Soares-Filho BS, Nepstad DC, Curran LM, Cerqueira GC, Garcia RA, et al. Modelling conservation in the Amazon basin. Nature. 2006;440:520-3. 
51. Zimmerman RH. Ecology of malaria vectors in the Americas and future direction. Mem Inst Oswaldo Cruz. 1992;87 Suppl 111:371-83.

52. Patz JA, Olson SH. Malaria risk and temperature: Influences from global climate change and local land use practices. Proc Natl Acad Sci USA. 2006;103(15):5635-6.

53. Pan American Health Organization. Report on the situation of Malaria in the Americas, 2008. 2009. Washington D.C., http://new.paho.org/hq/index. php?option=com_content\&task=view\&id=2459\&/temid=2049. Accessed 15 April 2015.

54. Hansen MC, Potapov PV, Moore R, Hancher M, Turubanova SA, et al. HighResolution Global Maps of 21st-Century Forest Cover Change. Science. 2013; 342:850-53. http://earthenginepartners.appspot.com/science-2013-globalforest. Accessed 30 May 2014.

Submit your next manuscript to BioMed Central and we will help you at every step:

- We accept pre-submission inquiries

- Our selector tool helps you to find the most relevant journal

- We provide round the clock customer support

- Convenient online submission

- Thorough peer review

- Inclusion in PubMed and all major indexing services

- Maximum visibility for your research

Submit your manuscript at www.biomedcentral.com/submit
Biomed Central 